\title{
Mastication, swallowing, and salivary flow in patients with head and neck cancer: objective tests versus patient-reported outcomes
}

\author{
Jorine A. Vermaire ${ }^{1}$. Cornelis P. J. Raaijmakers ${ }^{1} \cdot$ Irma M. Verdonck-de Leeuw ${ }^{2,3}$ (1) $\cdot$ Femke Jansen $^{2}$. \\ C. René Leemans ${ }^{2,3}$. Chris H. J. Terhaard ${ }^{1}$. Caroline M. Speksnijder ${ }^{4,5}$ (i)
}

Received: 8 March 2021 / Accepted: 14 June 2021 / Published online: 25 June 2021

(c) The Author(s) 2021

\begin{abstract}
Purpose Before and after treatment for head and neck cancer (HNC), many patients have problems with mastication, swallowing, and salivary flow. The aim of this study was to investigate the association between objective test outcomes of mastication, swallowing, and salivary flow versus patient-reported outcomes (PROs) measuring mastication-, swallowing-, and salivary flow-related quality of life.

Methods Data of the prospective cohort "Netherlands Quality of Life and Biomedical Cohort Study" was used as collected before treatment, and 3 and 6 months after treatment. Spearman's rho was used to test the association between objective test outcomes of the mixing ability test (MAT) for masticatory performance, the water-swallowing test (WST) for swallowing performance, and the salivary flow test versus PROs (subscales of the EORTC QLQ-H\&N35, Swallow Quality of Life questionnaire (SWAL-QoL-NL) and Groningen Radiation-Induced Xerostomia (GRIX)).

Results Data of 142 patients were used, and in total, 285 measurements were performed. No significant correlations were found between the MAT or WST and subscales of the EORTC QLQ-H\&N35. Significant but weak correlations were found between the MAT or WST and 4 subscales of the SWAL-QoL-NL. Weak to moderate correlations were found between the salivary flow test and GRIX at 3 and 6 months after treatment, with the highest correlation between salivary flow and xerostomia during the day (Spearman's rho $=-0.441, p=0.001$ ).

Conclusion The association between objective test outcomes and PROs is weak, indicating that these outcome measures provide different information about masticatory performance, swallowing, and salivary flow in patients with HNC.
\end{abstract}

Keywords EORTC QLQ-H\&N35 · GRIX · Head and neck cancer · Mixing ability test · Objective versus subjective data · Salivary flow test $\cdot 100-\mathrm{mL}$ water swallow test $\cdot$ SWAL-QoL-NL

Caroline M. Speksnijder

C.M.Speksnijder@umcutrecht.nl

1 Department of Radiation Oncology, Imaging Division, University Medical Center Utrecht, Utrecht University, Utrecht, The Netherlands

2 Department of Otolaryngology-Head and Neck Surgery and Cancer Center Amsterdam, Amsterdam UMC, Vrije Universiteit Amsterdam, Amsterdam, The Netherlands

3 Department of Clinical, Neuro- and Developmental Psychology, Amsterdam Public Health Research Institute, Vrije Universiteit Amsterdam, Amsterdam, The Netherlands

4 Department of Oral and Maxillofacial Surgery and Special Dental Care, University Medical Center Utrecht, Utrecht University, Heidelberglaan 100, PO Box 85.500, 3508 GA Utrecht, The Netherlands

5 Department of Head and Neck Surgical Oncology, University Medical Center Utrecht, Utrecht University, Utrecht, The Netherlands

\section{Introduction}

Head and neck cancer (HNC) is the seventh most common cancer worldwide, most often caused by alcohol and tobacco use, or the human papilloma virus (HPV) [1]. Treatment options for HNC (e.g., oral, pharyngeal, or laryngeal cancer) include surgery, radiation therapy (RT), and chemoradiation therapy (CRT). After treatment, patients may suffer from tissue fibrosis, osteoradionecrosis, xerostomia, or dysphagia. Deterioration in oral functioning (such as mastication, swallowing, saliva production, taste, dental condition, and speech) can result in complications such as malnutrition, dehydration, aspiration, and subsequent pneumonia. Within the first year after radiotherapy, approximately half of the HNC survivors experience difficulties with oral functioning, and unmet survivorship needs are common [2]. HNC 
survivors may experience psychosocial problems such as social isolation and depression, which decreases a person's quality of life (QoL) [3-5].

To determine oral functioning before and after treatment, objective and subjective measures can be used. Objective measurements are based on how well a person can perform a task, irrespective of what they experience while performing the task. They are based upon an accurate representation of the world, and are therefore unbiased because they record only what is observed, without adding or taking away from the observation $[6,7]$. A person's subjective evaluation depends on individual values and priorities, which may differ between persons and even within persons. This subjective evaluation, or patient-reported outcome measure (PRO), is based on what people actually experience, and is increasingly being integrated in routine clinical practice $[8$, 9]. It has shown to contribute to improved communication, patient satisfaction, earlier detection of problems and subsequently earlier referral, and more efficient use of health services [8]. In order to develop strategies to reduce side effects of oncological treatment, it is important to know the relation between the patients' subjective evaluation of his/ her oral functioning and the objective function of the various organs involved. In previous research, multiple studies looked at this relation between objective and subjective measurements, especially comparing swallowing outcomes [10-13]. However, many different measures have been used, and there is a lack of consensus about a preferred method to measure swallowing performance [10]. In addition, most studies focus only on one part of oral functioning, or at one point in time. Therefore, in this paper, objective measures and PROs are compared for three main oral functions (mastication, swallowing, and salivary flow), using the same methodology in a large group of patients at different time points.

To measure more aspects of oral functioning in time, and in particular masticatory performance, dysphagia, and xerostomia, different tests can be used. Objective masticatory performance can be measured with, for example, comminution methods, sieving and optical scanning methods, gummy jelly as test food, and mixing ability methods [14]. One method using the mixing ability method (the mixing ability test (MAT)) has proven to be highly reliable in patients with HNC [15]. Objective swallowing performance can be measured with, for example, fiberoptic endoscopic evaluation of swallowing (FEES), or in a non-invasive and fast manner with minimal equipment using a $100-\mathrm{mL}$ water swallow test (WST) $[16,17]$. Measures of objective salivary flow rate from parotid and submandibular glands have been used for years to determine the dose-response relationship between RT dose and degree of hyposalivation or sticky saliva [18].

Subjective oral functioning can be measured with several validated questionnaires [19]. The European Organization for Research and Treatment of Cancer Quality of
Life Core Questionnaire, Head and Neck module (EORTC QLQ-H\&N35), was especially developed to measure HNCspecific problems and addresses different items of oral functioning [20]. The Dutch version of the Swallow Quality of Life questionnaire (SWAL-QoL-NL) was developed to address swallowing-specific problems [21]. The Groningen Radiation-Induced Xerostomia (GRIX) questionnaire was developed to observe xerostomia and sticky saliva during day and night [22]. Before creating prediction models that show patients at risk for developing mastication-, dysphagia-, or xerostomia-related problems after treatment, it is important to get insight in the association between objective and subjective measures to get a total image of oral functioning. Therefore, the aim of this study was to determine the association between the MAT, WST, or salivary flow test and the EORTC QLQ-H\&N35, SWAL-QoL-NL or GRIX, before treatment, and 3 and 6 months after treatment.

\section{Methods}

Data of the prospective cohort study Netherlands Quality of Life and Biomedical Cohort (Net-Qubic) Study were used [23]. Patients were recruited between 2014 and 2018 and included when they were 18 years or older, diagnosed with oral, oropharyngeal, hypopharyngeal, laryngeal, or unknown primary HNC. Patients with recurrent or residual disease, with cognitive impairments, and having trouble understanding or reading the Dutch language were excluded. The study protocol was approved by the Medical Ethics Committee (NL45051.029.13). In the present study, the study population consisted of patients with data on MAT, WST, and salivary flow test. These tests were only performed in one single center (University Medical Center Utrecht (UMCU)). Sociodemographic and clinical data about age, sex, tumor stage, tumor location, and treatment were collected from medical records. All participants signed informed consent. Data from objective tests and subjective questionnaires were used as collected before primary treatment (baseline, M0), 3 months after treatment (M3), and 6 months after treatment (M6). Patients that did not perform both objective and subjective measures at one time point were excluded. A comparison between objective and subjective data was based on assumptions regarding best fit of subjective data to objective data.

\section{Mixing ability test}

The MAT consists of two layers of wax, with the colors red and blue (Plasticine modelling wax, non-toxic DIN EN-71, art. nos. crimson 52,801 and blue 52,809, Stockmar, Kalten Kirchen, Germany) [24]. The total thickness is $3 \mathrm{~mm}$, with a diameter of $30 \mathrm{~mm}$. The outcome variable ranges between 5 and 30, where a lower score implies a better mixed tablet 
and better masticatory performance. A subject was asked to chew on this tablet 20 times in order to mix the two colors. The tablet is then flattened, pressed to a thickness of $2 \mathrm{~mm}$, and scanned on both sides using a high-quality scanner (Epson ${ }^{\circledR}$ V750, Long Beach, CA, USA). The scanned images are then processed using Adobe Photoshop CS3 extended (Adobe, San Jose, CA, USA). The histograms of both sides of the flattened and scanned wax tablet are added to obtain red and blue intensity distributions. The spread of the color intensities is measured [24]. In previous research, this test has proven to be highly reliable in patients with HNC $(\mathrm{ICC}=0.886)[15]$.

\section{$100-\mathrm{mL}$ water swallow test}

During the WST, a subject was asked to drink $100 \mathrm{~mL}$ of water as quickly as is comfortably possible. The time to swallow this $100 \mathrm{~mL}$ (in seconds) and the number of swallows were counted, both by the subject and the researcher. Timing started when the water touched the bottom lip, and stopped when the larynx came to rest after the last swallow [25]. Persons failed the test when they coughed or choked post swallow, had a wet voice quality post swallow, or were unable to drink the whole $100 \mathrm{~mL}$ [17]. When a person was unable to drink the $100 \mathrm{~mL}$, the residual water was measured and noted. In a previous research, this test has proven to be highly reliable in patients with $\mathrm{HNC}$ (ICC $=0.923$ for number of swallows, and ICC $=0.893$ for duration) [26].

\section{Saliva collection}

Salivary flow was collected simultaneously from the floor of mouth (mainly submandibular gland) using a pipette, and from the left and right parotid gland using Lashley cups, as first described in 1981 [18]. The cups were placed over the orifice of the Stenson's duct. Stimulation of the glands was achieved by applying one drop of citric acid to the mobile part of the tongue every minute, and collection was carried out for $10 \mathrm{~min}$. The volume of saliva was measured as collected in tubes by weight, assuming the density of saliva as $1 \mathrm{~g} / \mathrm{ml}$. The flow rate was expressed in milliliters per $10 \mathrm{~min}$ $(\mathrm{ml} / 10 \mathrm{~min}$ ) for both parotid glands and the submandibular gland. In the present study, we used the total amount of saliva by adding up the saliva of both parotid glands and the submandibular gland. No oral stimulus was permitted for at least 30 min before saliva collection, including the WST and MAT [27]. In previous research, this test scored an ICC of 0.66 and 0.63 for the left and right parotid flow glands, indicating moderate test-retest reliability [28].

\section{EORTC QLQ-H\&N35}

The EORTC QLQ-H\&N35 is an additional questionnaire to the EORTC QLQ-C30 (core instrument), and widely used to measure QoL in patients with HNC [20]. It consists of 7 subscales: pain in the mouth (4 items), problems with swallowing (4 items), senses ( 2 items), speech (3 items), social eating (4 items), social contact (5 items), sexuality ( 2 items), and 11 single items which address problems with teeth, opening mouth, dry mouth, sticky saliva, coughing, feeling ill, painkillers, nutritional supplements, feeding tube, weight loss, and weight gain [29]. The scores are transformed to a scale of 0 to 100 , with a higher score on the symptom scales implying a higher level of symptoms or problems [20]. In the present study, we used the subscales "pain in mouth" and "social eating," and the single items "teeth," "opening mouth," "weight loss," and "weight gain" to explore the association between these PROs and the MAT. The subscales "pain in mouth" and "problems with swallowing," and the single items "dry mouth," "coughing," and "feeding tube" were used to explore the association between these PROs and the WST. The single items "dry mouth" and "sticky saliva" were used to explore the association between these PROs and the salivary output. This questionnaire performs well on internal consistency and construct validity, and is able to differentiate between diverse groups of patients regarding treatment, tumor size, time elapsed since treatment, and age [30]. In patients with HNC, Cronbach's $\alpha$ ranges from 0.75 to 0.93 for most scales, indicating satisfactory internal consistency [20,31].

\section{SWAL-QOL-NL}

The SWAL-QoL-NL consists of 39 items on 9 subscales: general burden, food selection, eating duration, eating desire, fear of eating, mental health, social functioning, and symptoms [21, 29]. After completing, a total SWAL-QoL-NL score could be calculated based on 23 items (item 1-9 and 12-25). The scores range from 0 to 100 , with a higher score indicating more impairment [29]. In the present study, we used the subscales "food selection," "eating duration," "eating desire," "fear of eating," and the total score to explore the association between these PROs and the MAT. We used the subscales "general burden," "symptoms," and the total score the explore the association between these PROs and the WST. Cronbach's $\alpha$ ranges from 0.79 to 0.95 in patients with oropharyngeal dysphagia, and intraclass correlations range from 0.59 to 0.91 , indicating excellent scale reliability [32]. 


\section{GRIX}

The GRIX consists of 14 questions and four subscales: xerostomia during day and night, and sticky saliva during day and night [22]. The scores were transformed to a scale from 0 to 100 , with a higher score indicating more problems regarding xerostomia or sticky saliva. Total xerostomia and sticky saliva were calculated by adding up the day and night scores to get a score from 0 to 200. In the present study, all subscales were used to explore the association between the PROs and salivary flow. Cronbach's $\alpha$ of these scales ranges between 0.82 and 0.94 , and test-retest reliability was between 0.63 and 0.67 , indicating moderate correlations [22].

\section{Statistical analyses}

Data were tested for normality using a Shapiro-Wilk test. The associations between the WST, MAT, and salivary flow versus PROs were tested using Spearman's rank correlation coefficient. The spearman correlation coefficient was categorized as very weak ( 0.0 to 0.1$)$, weak ( 0.1 to 0.39 ), moderate ( 0.4 to 0.69$)$, strong ( 0.7 to 0.89 ), and very strong (0.9 to 1.0) [33]. Scatterplots were created to visualize the MAT, WST, and salivary flow outcomes that had the highest correlation with one of the PROs. All analyses were performed using Statistical Package for the Social Sciences (SPSS) version 25 (Chicago, IL). A Bonferroni correction was used to account for the number of tests performed, in order to avoid a type I error [34]. This correction was calculated by dividing the p-value by the number of tests performed. The corrected p-value was $0.05 / 12=0.004$ for the MAT, $0.05 / 8=0.006$ for the WST, and $0.05 / 8=0.006$ for the salivary flow. A $p$-value $\leq 0.004$ or 0.006 was considered statistically significant.

\section{Results}

The study cohort consisted of 142 patients out of the total Net-Qubic cohort in the UMCU $(N=154)$, of which 64 patients had repeated measurements for the MAT and WST at M0, M3, and M6. Twenty of these 142 patients had repeated measurements for the salivary flow measurements at M0, M3, and M6. Characteristics of patients can be found in Table 1. In total, 285 assessments for the MAT and WST were carried out: 101 at M0, 92 at M3, and 92 at M6. For the salivary flow measurements, 167 assessments were carried out: 45 at M0, 65 and M3, and 57 at M6. All data except the MAT at M0 and M6 were not normally distributed. Boxplots displaying the outcomes of the objective measurements can be found in Fig. 1. Regarding WST, there were missing data in 6 patients at M0 (5 patients because they were unable to drink the $100 \mathrm{~mL}$, and 1 patient because of choking or coughing post swallow), in 12 patients at M3 (9 because they choked or coughed post swallow, and 3 because they were unable to drink the $100 \mathrm{~mL}$ ), and in 9 patients at M6 (6 because they choked or coughed post swallow, and 3 because they were unable to drink the $100 \mathrm{~mL}$ ).

\section{MAT versus PROs}

The associations between MAT and subscales of the EORTC QLQ-H\&N35 were not statistically significant at M0, M3, and M6 (Table 2). The association between the MAT and subscales of the SWAL-QoL-NL showed weak significant correlations at M0 for the items food selection (Spearman's $\rho=0.347, p=0.001$ ), eating duration (Spearman's $\rho=0.361$, $p<0.001$ ), fear of eating (Spearman's $\rho=0.336, p=0.001$ ), and total SWAL-QoL-NL score (Spearman's $\rho=0.310$, $p=0.002$ ). No significant correlations were found at M3 and M6. As an example, Fig. 2a displays the MAT versus the eating duration at M0. Correlations between the MAT and all items of the EORTC QLQ-H\&N35, SWAL-QoL-NL, and GRIX are shown in Appendixes 1, 2, and 3, respectively.

\section{WST versus PROs}

The association between the PROs and the WST was calculated for both the number of swallows and the swallowing duration (Table 3). The association between the number of swallows and subscales of the EORTC QLQ-H\&N35 showed no significant correlations at M0, M3, and M6. The association between the number of swallows and subscales of the SWAL-QoL-NL showed no significant correlations at M0 and M3. Weak significant correlations were found at M6 for the item total SWAL-QoL-NL score (Spearman's $\rho=0.335, p=0.001)$. The association between swallowing duration and subscales of the EORTC QLQ-H\&N35 showed no significant correlations at M0, M3, and M6. The association between duration and subscales of the SWAL-QoL-NL showed no significant correlations at M0. At M3, weak significant correlations were found for the items food selection (Spearman's $\rho=0.332, p=0.001$ ) and total SWAL-QoL-NL score (Spearman's $\rho=0.353, p=0.001$ ). At M6, weak significant correlations were found for the item total SWALQoL-NL score (Spearman's $\rho=0.398, p<0.001$ ). As example, Fig. $2 b$ displays the total score on the SWAL-QoL-NL questionnaire versus the number of swallows of the WST, and Fig. 2c displays the total score on the SWAL-QoL-NL questionnaire versus the duration of the WST, both at M6. Correlations between the WST and all items of the EORTC QLQ-H\&N35, SWAL-QoL-NL, and GRIX are shown in Appendixes 4, 5, and 6, respectively. 
Table 1 Characteristics of patients with HNC

\begin{tabular}{|c|c|c|c|c|c|c|c|c|}
\hline \multirow[b]{2}{*}{ Characteristics } & \multicolumn{4}{|c|}{ MAT and WST } & \multicolumn{4}{|c|}{ Salivary flow test } \\
\hline & $\operatorname{M0}(N=101)$ & M3 $(N=92)$ & M6 $(N=92)$ & $\begin{array}{l}\text { Repeated } \\
\text { measurements } \\
\mathrm{M} 0, \mathrm{M} 3 \text {, and } \mathrm{M} 6 \\
(N=64)\end{array}$ & $\mathrm{M} 0(N=45)$ & M3 $(N=65)$ & M6 $(N=57)$ & $\begin{array}{l}\text { Repeated } \\
\text { measurements } \\
\text { M0, M3, and M6 } \\
(N=20)\end{array}$ \\
\hline $\begin{array}{l}\text { Age (median, } \\
\text { IQR) }\end{array}$ & $64.0(15.5)$ & $64.0(13.8)$ & $63.5(13.8)$ & $63.5(14.0)$ & $61.8(16.0)$ & $63.2(15.0)$ & $62.1(13.5)$ & $64.0(11.0)$ \\
\hline \multicolumn{9}{|l|}{ Sex } \\
\hline Male & $77(76.2 \%)$ & $72(78.3 \%)$ & $69(75 \%)$ & $49(76.6 \%)$ & $34(75.6 \%)$ & $55(84.6 \%)$ & $45(78.9 \%)$ & $15(75.0 \%)$ \\
\hline Female & $24(23.8 \%)$ & $20(21.7 \%)$ & $23(25 \%)$ & $15(23.4 \%)$ & $11(24.4 \%)$ & $10(15.4 \%)$ & $12(21.1 \%)$ & $5(25.0 \%)$ \\
\hline \multicolumn{9}{|l|}{ Tumor site } \\
\hline Oropharynx & $36(35.6 \%)$ & $37(40.2 \%)$ & $34(37.0 \%)$ & $27(42.2 \%)$ & $14(31.1 \%)$ & $26(40.0 \%)$ & $23(40.4 \%)$ & $6(30.0 \%)$ \\
\hline Larynx & $29(28.7 \%)$ & $24(26.1 \%)$ & $25(27.2 \%)$ & $16(25.0 \%)$ & $15(33.3 \%)$ & $18(27.7 \%)$ & $14(24.6 \%)$ & $6(30.0 \%)$ \\
\hline Oral cavity & $27(26.7 \%)$ & $24(26.1 \%)$ & $26(28.3 \%)$ & $17(26.6 \%)$ & $11(24.4 \%)$ & $16(24.6 \%)$ & $16(28.1 \%)$ & $6(30.0 \%)$ \\
\hline Hypopharynx & $3(3.0 \%)$ & $0(0.0 \%)$ & $3(3.3 \%)$ & $0(0 \%)$ & $1(2.2 \%)$ & $0(0.0 \%)$ & $1(1.8 \%)$ & $0(0.0 \%)$ \\
\hline $\begin{array}{r}\text { Unknown } \\
\text { primary }\end{array}$ & $6(5.9 \%)$ & $7(7.6 \%)$ & $4(4.3 \%)$ & $4(6.3 \%)$ & $4(8.9 \%)$ & $5(7.7 \%)$ & $3(5.3 \%)$ & $2(10.0 \%)$ \\
\hline \multicolumn{9}{|l|}{ Tumor stage } \\
\hline I & $27(26.7 \%)$ & $22(23.9 \%)$ & $24(26.1 \%)$ & $16(25.0 \%)$ & $16(35.6 \%)$ & $16(24.6 \%)$ & $15(26.3 \%)$ & $6(30.0 \%)$ \\
\hline II & $20(19.8 \%)$ & $17(18.5 \%)$ & $20(21.7 \%)$ & $15(23.4 \%)$ & $8(17.8 \%)$ & $15(23.1 \%)$ & $12(21.1 \%)$ & $3(15.0 \%)$ \\
\hline III & $13(12.9 \%)$ & $13(14.1 \%)$ & $12(13.0 \%)$ & $6(9.4 \%)$ & $3(6.7 \%)$ & $7(10.8 \%)$ & $5(8.8 \%)$ & $2(10.0 \%)$ \\
\hline IV & $41(40.6 \%)$ & $40(43.5 \%)$ & $36(39.1 \%)$ & $27(42.2 \%)$ & $18(40.0 \%)$ & $27(41.5 \%)$ & $25(43.9 \%)$ & $9(45.0 \%)$ \\
\hline \multicolumn{9}{|l|}{ Primary treatment } \\
\hline RT & $44(43.6 \%)$ & $42(45.7 \%)$ & $41(44.6 \%)$ & $30(46.9 \%)$ & $21(46.7 \%)$ & $31(47.7 \%)$ & $24(42.1 \%)$ & $8(40.0 \%)$ \\
\hline CRT & $27(26.7 \%)$ & $25(27.2 \%)$ & $23(25.0 \%)$ & $18(28.1 \%)$ & $12(26.7 \%)$ & $17(26.2 \%)$ & $16(28.1 \%)$ & $7(35.0 \%)$ \\
\hline Surgery & $20(19.8 \%)$ & $16(17.4 \%)$ & $19(20.7 \%)$ & $11(17.2 \%)$ & $8(17.8 \%)$ & $12(18.5 \%)$ & $10(17.5 \%)$ & $4(20.0 \%)$ \\
\hline $\begin{array}{c}\text { Surgery with } \\
\text { PO(C)RT }\end{array}$ & $10(9.9 \%)$ & $9(9.8 \%)$ & $9(9.8 \%)$ & $5(7.8 \%)$ & $4(8.9 \%)$ & $5(7.7 \%)$ & $7(12.3 \%)$ & $1(5.0 \%)$ \\
\hline
\end{tabular}

$M O$ before treatment, $M 33$ months after treatment, $M 66$ months after treatment; $C R T$ chemoradiation therapy, $I Q R$ interquartile range, $P O(C)$ $R T$ post-operative (chemo) radiation therapy, $R T$ radiation therapy

\section{Salivary flow versus PROs}

The association between total salivary flow and subscales of the EORTC QLQ-H\&N35 and GRIX showed no significant differences at M0 (Table 4). At M3, weak significant differences were found for dry mouth (Spearman's $\rho=-0.339, p=0.004$ ) and sticky saliva (Spearman's $\rho=-0.321, p=0.006)$ on the EORTC QLQ-H\&N35, and for xerostomia during the day (Spearman's $\rho=-0.332$, $p=0.006$ ) on the GRIX questionnaire. At M6, weak significant differences were found for the item sticky saliva (Spearman's $\rho=-0.350, p=0.006$ ) on the EORTC QLQ-H\&N35 and for the item sticky saliva during the day (Spearman's $\rho=-0.348, p=0.006$ ) on the GRIX questionnaire. A moderate correlation was found for the item xerostomia during the day (Spearman's $\rho=-0.441$, $\mathrm{p}=0.001)$ on the GRIX questionnaire. As an example, Fig. 2d displays xerostomia during the day versus total saliva at M6. Correlations between total salivary flow and all items of the EORTC QLQ-H\&N35 and SWAL-QoLNL can be found in Appendices 7 and 8, respectively.

\section{Discussion}

This study investigated associations between objective tests of mastication, swallowing, and salivary production and patient-reported outcomes. The associations between objective tests and PROs were weak (correlation below 0.40) for all items, except one: a moderate correlation between xerostomia during the day versus total salivary flow at M6 (Spearman's $\rho=-0.441, p=0.001$ ). In addition, none of the items on the EORTC QLQ-H\&N35 questionnaire showed a significant correlation to the MAT or to the WST. Even when focusing on patients with the highest $10 \%$ scores on the MAT or WST, indicating worst masticatory or swallowing performance (see the top part in Fig. 2a-c), there was still a large variation of scores on the PROs taking up almost 
Fig. 1 Boxplots displaying all objective measurements at M0, M3, and M6 for the MAT (a), number of swallows on the WST (b), duration of swallowing on the WST (c), and total salivary flow $(\mathbf{d})$, respectively
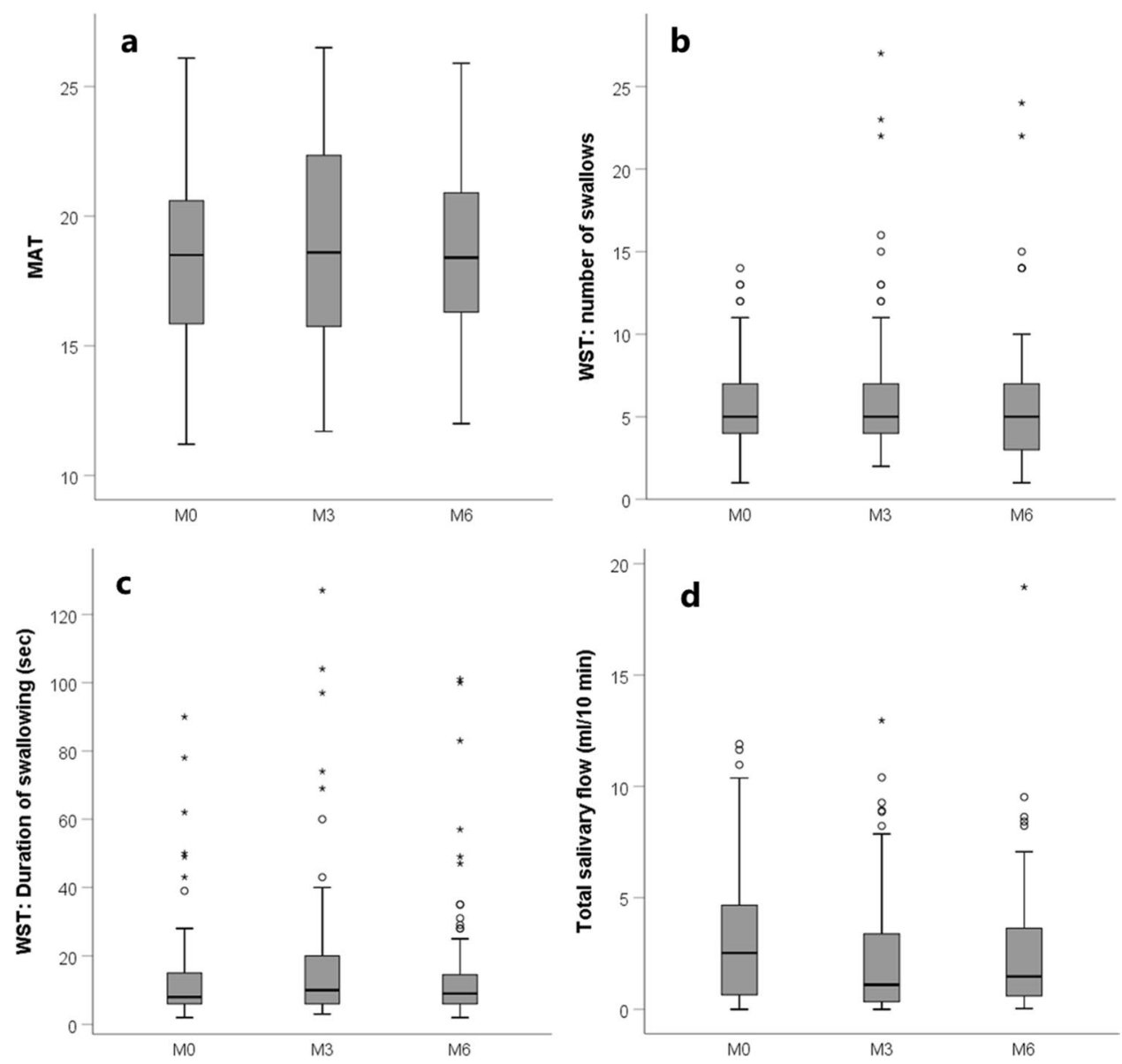

Table 2 Spearman correlation coefficients of the MAT versus the EORTC QLQ-H\&N35 and SWAL-QoL-NL

\begin{tabular}{|c|c|c|c|c|c|c|}
\hline \multirow[t]{2}{*}{ MAT } & \multicolumn{2}{|l|}{$\operatorname{M0}(N=101)$} & \multicolumn{2}{|l|}{ M3 $(N=92)$} & \multicolumn{2}{|l|}{$\operatorname{M6}(N=92)$} \\
\hline & Spearman's $\rho$ & $p$-value & Spearman's $\rho$ & $p$-value & Spearman's $\rho$ & $p$-value \\
\hline \multicolumn{7}{|l|}{ EORTC QLQ-H\&N35 } \\
\hline Pain in mouth & 0.082 & 0.417 & 0.066 & 0.541 & -0.014 & 0.896 \\
\hline Trouble with social eating & 0.141 & 0.166 & 0.276 & $0.009^{*}$ & 0.201 & 0.054 \\
\hline Teeth & -0.004 & 0.972 & 0.097 & 0.368 & 0.106 & 0.313 \\
\hline Opening mouth & 0.026 & 0.803 & 0.211 & $0.048^{*}$ & -0.028 & 0.792 \\
\hline Feeding tube & -0.102 & 0.319 & 0.146 & 0.173 & -0.040 & 0.703 \\
\hline Weight loss & -0.119 & 0.247 & -0.004 & 0.968 & -0.009 & 0.936 \\
\hline Weight gain & 0.058 & 0.571 & 0.004 & 0.970 & 0.086 & 0.412 \\
\hline \multicolumn{7}{|l|}{ SWAL-QoL-NL } \\
\hline Food selection & 0.347 & $0.001 * \dagger$ & 0.227 & $0.034^{*}$ & 0.232 & $0.026^{*}$ \\
\hline Eating duration & 0.361 & $<0.001^{* \dagger}$ & 0.154 & 0.152 & 0.185 & 0.078 \\
\hline Eating desire & 0.167 & 0.105 & 0.014 & 0.900 & 0.211 & $0.043 *$ \\
\hline Fear of eating & 0.336 & $0.001 * \dagger$ & 0.172 & 0.108 & 0.163 & 0.119 \\
\hline Total score & 0.310 & $0.002 * \dagger$ & 0.165 & 0.124 & 0.222 & $0.033 *$ \\
\hline
\end{tabular}

MO before treatment, M3 3 months after treatment, M6 6 months after treatment

* $p \leq 0.05$

${ }^{\dagger} p \leq 0.004$ (Bonferroni correction) 

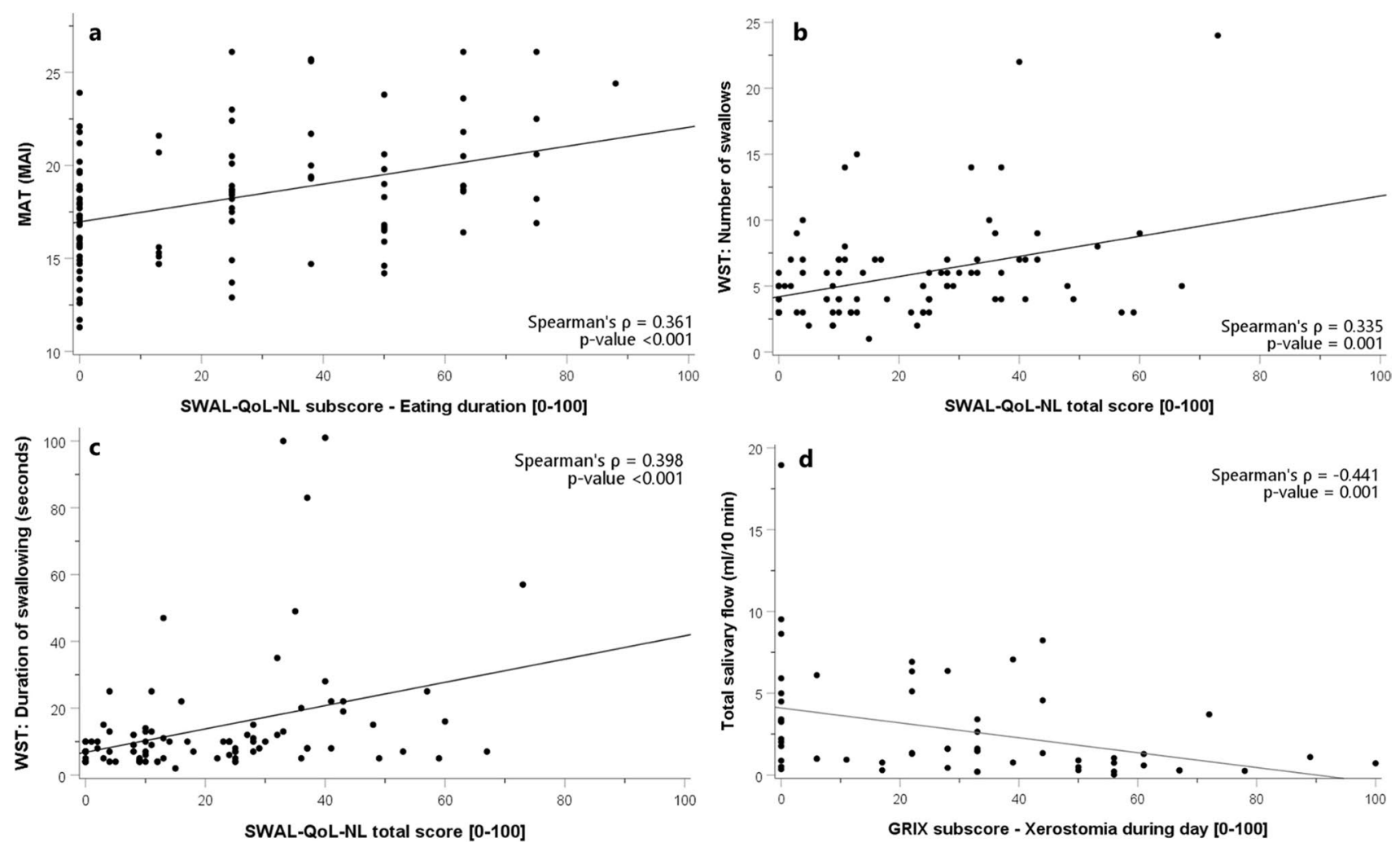

Fig. 2 Scatterplots displaying the highest correlation for each objective measure; the eating duration on the SWAL-QoL-NL versus the MAT at M0 (a), the total score on the SWAL-QoL-NL questionnaire

versus the number of swallows on the WST at M6 (b), and duration at M6 (c), and the xerostomia by day versus the total amount of saliva at M6 (d), respectively

the entire scale. These findings indicate that the objective tests used in this research do not measure the same construct as the used PROs.

Our findings are in line with previous research in patients with $\mathrm{HNC}$ that showed that clinical measures and PROs generally correlate poorly $[10,12,35]$. For example, swallowing research showed weak to strong associations between the $100 \mathrm{~mL}$ WST and the MD Anderson Dysphagia Inventory (MDADI) questionnaire (a questionnaire similar to the SWAL-QoL) [10]. Research about salivary measurements found weak associations between salivary flow and xerostomia scores [36]. Other research stated that the EORTC quality of life questionnaire provided valuable data on subjective complaints, but that these complaints are not closely correlated with specific objective changes [37].

Previous research in patients with Parkinson's disease and patients with schizophrenia showed that objective and subjective measures were not interchangeable, and each has a unique contribution to the problems assessed [38, 39]. Both objective and subjective measures may predict QoL in these patients [38]. Using PROs alone does not seem to measure function the same way functional tests do, and therefore should be combined with other data sources [9]. PROs are designed to assess how a patient evaluates his or her

functioning rather than actual performance [40]. In addition, functional disorders measured via instrumental assessments by clinicians may not have a strong relationship with how patients perceive this disorder. Patients are more likely to rate their symptoms more severely than do clinicians, which can lead to an underestimation of side effects post-treatment [41]. Before selecting a measurement method, it is therefore important to identify the purpose of the measurement. For instance, when the effect of swallowing muscle sparing with $\mathrm{RT}$ is assessed, it is important to objectively test swallowing function. Whereas when the goal is to evaluate the effect of swallowing muscle sparing RT on perceived swallowing function of patients, it is important to use PROs. When only PROs are measured, it can be difficult to determine the cause of the reduced swallowing sensation. Individuals differ in what they find important, and expectations about one's progress after treatment may change over time and in response to personal circumstances. Patients may develop a degree of adaptation over time, in which their PRO outcomes improve, but swallowing dysfunction stays the same or worsens [11]. Their subjective feeling of QoL also depends on satisfaction with, physical, material, emotional, and social well-being, and their development and activity. Objective observations record only what is observed; they are a representation of 


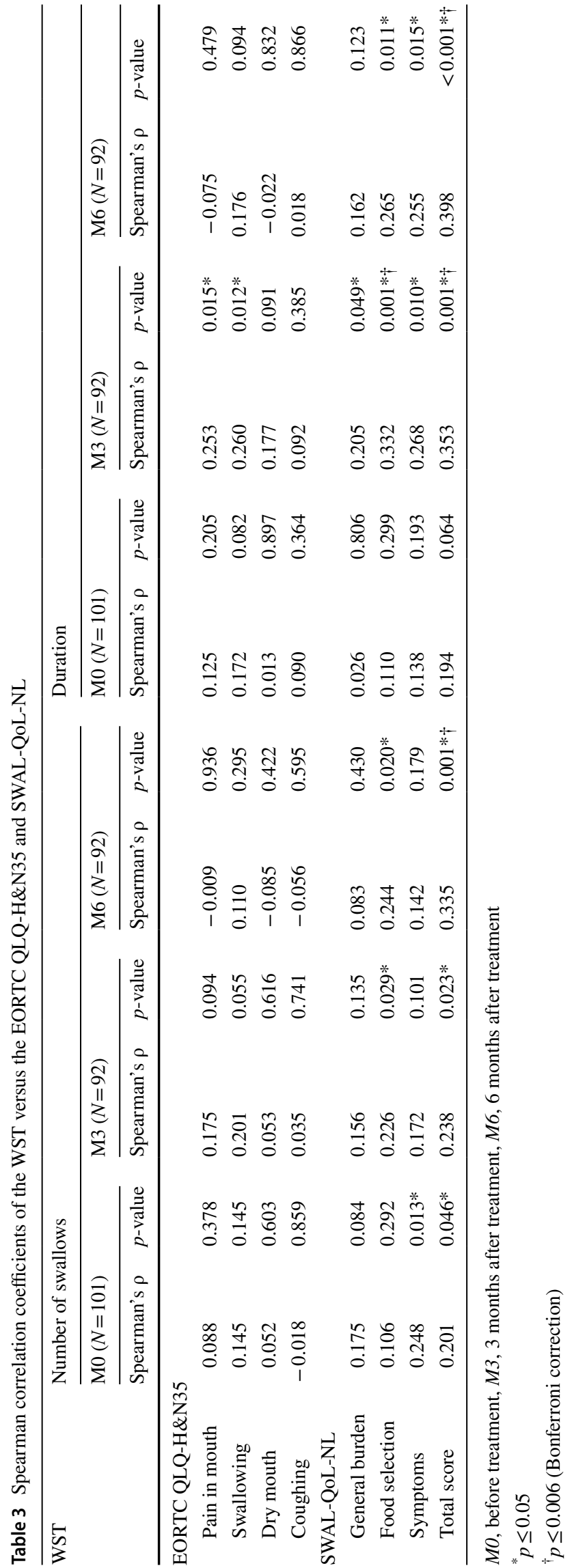

how something is [42]. The MAT, for example, reflects a complex process of oral muscle movements and coordination, which is difficult to answer with one single question in a questionnaire. Unfortunately, the loss of teeth, dental decay, and periodontal health were not assessed in this research, and may play an important role in oral functioning as well [37].

A limitation of this study was that the number of salivary flow measurements performed was smaller in comparison to that of the masticatory performance and swallowing measurements. Therefore, it is possible that these measurements are less reliable due to insufficient power. The salivary flow measurements were much more time-consuming, and difficulties occurred with the attachment of the Lashley cups. Therefore, it was chosen to combine the submandibular flow with the parotid flow and use the total flow to determine the associations between objective and subjective measures. Although these associations regarding xerostomia were higher in comparison to those of masticatory performance and swallowing measurements, a prerequisite should be that the objective test is easy and fast to perform, in order to be a valuable addition to PROs. A recommendation would therefore be to use an easy and fast test for measuring saliva flow, for example, by spitting saliva produced over a period of time in a plastic tube, with and without stimulation [43].

The SWAL-QoL-NL questionnaire is especially designed to detect swallowing problems. However, there is a close relationship between swallowing and mastication, as seen in multiple items such as "food selection," "eating duration," "eating desire," and "fear of eating." This relationship also comes across in many items of, e.g., the MDADI questionnaire [44]. When the focus is on swallowing-specific problems, it is therefore recommended to use swallowing-specific questions only, in combination with an objective swallowing test.

As shown in previous research, the reliability of the MAT, WST, EORTC QLQ-H\&N35, and SWAL-QoL-NL was high, with a reliability of 0.886 for the MAT, and 0.893 and 0.923 for the WST. The reliability of the questionnaires was between 0.75 and 0.95 , indicating that all measures are reliable to use in patients with $\mathrm{HNC}[15,20,26,31,32]$. This study provides insight in the (weak) association between these objective and subjective measures. The results are important to take into account when developing prediction models to identify patients at risk for developing mastication, dysphagia, or xerostomia problems after treatment. Consistent with previous research, the results in this paper show that objective and subjective measures do not seem to measure the same construct, and therefore, separate prediction models with objective and subjective outcomes should be created, dependent on the aim of the model. 
Table 4 Spearman correlation coefficients of salivary flow versus the EORTC QLQ$\mathrm{H} \& \mathrm{~N} 35$ and GRIX

\begin{tabular}{|c|c|c|c|c|c|c|}
\hline \multirow[t]{2}{*}{ Total salivary flow } & \multicolumn{2}{|l|}{$\operatorname{M0}(N=45)$} & \multicolumn{2}{|l|}{$\mathrm{M} 3(N=65)$} & \multicolumn{2}{|l|}{$\operatorname{M6}(N=57)$} \\
\hline & Spearman's $\rho$ & $p$-value & Spearman's $\rho$ & $p$-value & Spearman's $\rho$ & $p$-value \\
\hline \multicolumn{7}{|l|}{ EORTC QLQ-H\&N35 } \\
\hline Dry mouth & -0.227 & 0.126 & -0.339 & $0.004 * \dagger$ & -0.279 & $0.031 *$ \\
\hline Sticky saliva & -0.217 & 0.143 & -0.321 & $0.006^{*} \dagger$ & -0.350 & $0.006^{* \dagger}$ \\
\hline \multicolumn{7}{|l|}{ GRIX } \\
\hline Xerostomia during day & -0.254 & 0.092 & -0.332 & $0.006^{* \dagger}$ & -0.441 & $0.001 * \dagger$ \\
\hline Xerostomia during night & -0.147 & 0.329 & -0.225 & 0.063 & -0.099 & 0.450 \\
\hline Xerostomia total score & -0.182 & 0.232 & -0.327 & $0.008^{*}$ & -0.320 & $0.015^{*}$ \\
\hline Sticky saliva during day & -0.218 & 0.151 & -0.282 & $0.019 *$ & -0.348 & $0.006 * \dagger$ \\
\hline Sticky saliva during night & -0.299 & $0.044 *$ & -0.192 & 0.115 & -0.128 & 0.331 \\
\hline Sticking saliva total score & -0.271 & 0.072 & -0.274 & $0.023^{*}$ & -0.256 & $0.048 *$ \\
\hline
\end{tabular}

MO before treatment, M3 3 months after treatment, M6 6 months after treatment

* $\mathrm{p} \leq 0.05$

${ }^{\dagger} \mathrm{p} \leq 0.006$ (Bonferroni correction)

\section{Conclusion}

This study showed significant but weak associations between objective tests of masticatory performance, swallowing, and salivary performance and patient-reported outcomes. It is therefore important to measure mastication-, dysphagia-, and xerostomia-related problems in patients with HNC both objectively and subjectively. This will acquire unique information and will help create the complete picture of patients' perspective and functioning.

Supplementary Information The online version contains supplementary material available at https://doi.org/10.1007/s00520-021-06368-6.

Acknowledgements The authors would like to thank Diana Louis for performing the majority of the mixing ability tests (MAT), waterswallowing tests (WST), and salivary flow tests, and all patients for participating in the NET-QUBIC research.

Author contribution All authors contributed to the study conception and design, patient recruitment, and data collection. Data analyses were performed by Jorine A. Vermaire. The first draft of the manuscript was written by Jorine A. Vermaire, and all authors commented on previous versions of the manuscript. All authors read and approved the final manuscript.

Funding This study was carried out using the research infrastructure and data of the Netherlands Quality of life and Biomedical Cohort study on head and neck cancer (NET-QUBIC), sponsored by the Dutch Cancer Society/Alpe d'HuZes (grant number VU 2013-5930).

Data availability The collection and integration of large amounts of personal, biological, genetic, and diagnostic information precludes open access to the NET-QUBIC research data. In the section, data and sample dissemination (www.kubusproject.nl) describes how the data are made available for the research community.

Code availability Not applicable.

\section{Declarations}

Ethics approval The study protocol was approved by the Medical Ethics Committee of the Netherlands (NL45051.029.13), as part of the NET-QUBIC research and in line with the principles of the Declaration of Helsinki.

Consent to participate Written informed consent was obtained from all patients.

Consent for publication Patients signed informed consent regarding publishing their data.

Conflict of interest The authors declare no competing interests.

Open Access This article is licensed under a Creative Commons Attribution 4.0 International License, which permits use, sharing, adaptation, distribution and reproduction in any medium or format, as long as you give appropriate credit to the original author(s) and the source, provide a link to the Creative Commons licence, and indicate if changes were made. The images or other third party material in this article are included in the article's Creative Commons licence, unless indicated otherwise in a credit line to the material. If material is not included in the article's Creative Commons licence and your intended use is not permitted by statutory regulation or exceeds the permitted use, you will need to obtain permission directly from the copyright holder. To view a copy of this licence, visit http://creativecommons.org/licenses/by/4.0/.

\section{References}

1. Rettig EM, D'Souza G (2015) Epidemiology of head and neck cancer. Surg Oncol Clin N Am 24(3):379-396. https://doi.org/ 10.1016/j.soc.2015.03.001

2. Ringash J, Bernstein LJ, Devins G, Dunphy C, Giuliani M, Martino R, McEwen S (2018) Head and neck cancer survivorship: learning the needs, meeting the needs. Seminars in radiation oncology 28(1):64-74. https://doi.org/10.1016/j.semradonc.2017. 08.008

3. Riffat F, Gunaratne DA, Palme CE (2015) Swallowing assessment and management pre and post head and neck cancer treatment. 
Curr Opin Otolaryngol Head Neck Surg 23(6):440-447. https:// doi.org/10.1097/MOO.0000000000000205

4. Kamal M, Rosenthal DI, Volpe S, Goepfert RP, Garden AS, Hutcheson KA, Al Feghali KA, Meheissen MAM, Eraj SA, Dursteler AE, Williams B, Smith JB, Aymard JM, Berends J, White AL, Frank SJ, Morrison WH, Cardoso R, Chambers MS, Sturgis EM, Mendoza TR, Lu C, Mohamed ASR, Fuller CD, Gunn GB (2018) Patient reported dry mouth: instrument comparison and model performance for correlation with quality of life in head and neck cancer survivors. Radiother Oncol 126(1):75-80. https://doi.org/10.1016/j.radonc.2017.10.037

5. Hamlet S, Faull J, Klein B, Aref A, Fontanesi J, Stachler R, Shamsa F, Jones L, Simpson M (1997) Mastication and swallowing in patients with postirradiation xerostomia. Int $\mathrm{J}$ Radiation Oncology Biol 37(4):789-796

6. Buitenweg DC, Bongers IL, van de Mheen D, van Oers HAM, van Nieuwenhuizen C (2018) Subjectively different but objectively the same? Three profiles of QoL in people with severe mental health problems. Qual Life Res 27(11):2965-2974. https://doi.org/10. 1007/s11136-018-1964-7

7. Mascolo MF (2016) Beyond objectivity and subjectivity: the intersubjective foundations of psychological science. Integr Psychol Behav Sci 50(4):543-554. https://doi.org/10.1007/ s12124-016-9357-3

8. Papadakos JK, Charow RC, Papadakos CJ, Moody LJ, Giuliani ME (2019) Evaluating cancer patient-reported outcome measures: readability and implications for clinical use. Cancer 125(8):1350 1356. https://doi.org/10.1002/cncr.31928

9. Wolpert M (2014) Uses and abuses of patient reported outcome measures (PROMs): potential iatrogenic impact of PROMs implementation and how it can be mitigated. Adm Policy Ment Health 41(2):141-145. https://doi.org/10.1007/s10488-013-0509-1

10. Pedersen A, Wilson J, McColl E, Carding P, Patterson J (2016) Swallowing outcome measures in head and neck cancer-How do they compare? Oral Oncol 52:104-108. https://doi.org/10.1016/j. oraloncology.2015.10.015

11. Frowen J, Drosdowsky A, Perry A, Corry J (2016) Long-term swallowing after chemoradiotherapy: prospective study of functional and patient-reported changes over time. Head Neck 38(Suppl 1):E307-315. https://doi.org/10.1002/hed.23991

12. Hedstrom J, Tuomi L, Finizia C, Olsson C (2018) Correlations between patient-reported dysphagia screening and penetrationaspiration scores in head and neck cancer patients post-oncological treatment. Dysphagia 33(2):206-215. https://doi.org/10.1007/ s00455-017-9847-6

13. Rogus-Pulia NM, Pierce MC, Mittal BB, Zecker SG, Logemann JA (2014) Changes in swallowing physiology and patient perception of swallowing function following chemoradiation for head and neck cancer. Dysphagia 29(2):223-233. https://doi.org/10. 1007/s00455-013-9500-y

14. Elgestad Stjernfeldt P, Sjogren P, Wardh I, Bostrom AM (2018) Systematic review of measurement properties of methods for objectively assessing masticatory performance. Clinical and experimental dental research 5(1):76-104. https://doi.org/10. $1002 /$ cre2.154

15. Vermaire JA, Weinberg FM, Raaijmakers CPJ, Verdonck-de Leeuw IM, Terhaard CHJ, Speksnijder CM (2020) Reliability of the mixing ability test testing masticatory performance in patients with head and neck cancer and healthy controls. J Oral Rehabil. https://doi.org/10.1111/joor.13029

16. Nathadwarawala KM, Nicklin J, Wiles CM (1992) A timed test of swallowing capacity for neurological patients. J Neurol Neurosurg Psychiatry 55(9):822-825. https://doi.org/10.1136/jnnp.55.9.822

17. Patterson JM, Hildreth A, McColl E, Carding PN, Hamilton D, Wilson JA (2011) The clinical application of the $100 \mathrm{~mL}$ water swallow test in head and neck cancer. Oral Oncol 47(3):180-184. https://doi.org/10.1016/j.oraloncology.2010.11.020

18. Baum BJ (1981) Evaluation of stimulated parotid saliva flow rate in different age groups. J Dent Res 60(7):1292-1296. https://doi. org/10.1177/00220345810600070101

19. van der Veen J, Nuyts S (2017) Can intensity-modulated-radiotherapy reduce toxicity in head and neck squamous cell carcinoma? Cancers 9(12):135. https://doi.org/10.3390/cancers910 0135

20. Bjordal K, de Graeff A, Fayers PM, Hammerlid E, van Pottelsberghe C, Curran D, Ahlner-Elmqvist M, Maher EJ, Meyza JW, Bredart A, Soderholm AL, Arraras JJ, Feine JS, Abendstein H, Morton RP, Pignon T, Huguenin P, Bottomly A, Kaasa S (2000) A 12 country field study of the EORTC QLQ-C30 (version 3.0) and the head and neck cancer specific module EORTC QLQ-H\&N35 in head and neck patients. EORTC Quality of Life Group. European journal of cancer 36(14):1796-1807. https://doi.org/10.1016/ s0959-8049(00)00186-6

21. Bogaardt HC, Speyer R, Baijens LW, Fokkens WJ (2009) Cross-cultural adaptation and validation of the Dutch version of SWAL-QoL. Dysphagia 24(1):66-70. https://doi.org/10.1007/ s00455-008-9174-Z

22. Beetz I, Burlage FR, Bijl HP, Hoegen-Chouvalova O, Christianen ME, Vissink A, van der Laan BF, de Bock GH, Langendijk JA (2010) The Groningen Radiotherapy-Induced Xerostomia questionnaire: development and validation of a new questionnaire. Radiother Oncol 97(1):127-131. https://doi.org/10.1016/j.radonc. 2010.05.004

23. Verdonck-de Leeuw IM, Jansen F, Brakenhoff RH, Langendijk JA, Takes R, Terhaard CHJ, Baatenburg de Jong RJ, Smit JH, Leemans CR (2019) Advancing interdisciplinary research in head and neck cancer through a multicenter longitudinal prospective cohort study: the NETherlands QUality of life and BIomedical Cohort (NET-QUBIC) data warehouse and biobank. BMC Cancer 19(1):765. https://doi.org/10.1186/s12885-019-5866-Z

24. Speksnijder CM, Abbink JH, van der Glas HW, Janssen NG, van der Bilt A (2009) Mixing ability test compared with a comminution test in persons with normal and compromised masticatory performance. Eur J Oral Sci 117(5):580-586. https://doi.org/10. 1111/j.1600-0722.2009.00675.x

25. Patterson JM, McColl E, Carding PN, Kelly C, Wilson JA (2009) Swallowing performance in patients with head and neck cancer: a simple clinical test. Oral Oncol 45(10):904-907. https://doi.org/ 10.1016/j.oraloncology.2009.03.012

26. Vermaire JA, Terhaard CH, Verdonck-de Leeuw I, Raaijmakers CP, Speksnijder CM (2021) Reliability of the $100 \mathrm{~mL}$ water swallow test in patients with head and neck cancer and healthy subjects. Head Neck. https://doi.org/10.1002/hed.26723

27. Houweling AC, Philippens ME, Dijkema T, Roesink JM, Terhaard $\mathrm{CH}$, Schilstra C, Ten Haken RK, Eisbruch A, Raaijmakers CP (2010) A comparison of dose-response models for the parotid gland in a large group of head-and-neck cancer patients. Int J Radiat Oncol Biol Phys 76(4):1259-1265. https://doi.org/10. 1016/j.ijrobp.2009.07.1685

28. Burlage FR, Pijpe J, Coppes RP, Hemels MEW, Meertens H, Canrinus A, Vissink A (2005) Variability of flow rate when collecting stimulated human parotid saliva. Eur J Oral Sci 113(5):386-390. https://doi.org/10.1111/j.1600-0722.2005.00241.x

29. Rinkel RN, Verdonck-de Leeuw IM, Langendijk JA, van Reij EJ, Aaronson NK, Leemans CR (2009) The psychometric and clinical validity of the SWAL-QOL questionnaire in evaluating swallowing problems experienced by patients with oral and oropharyngeal cancer. Oral Oncol 45(8):e67-71. https://doi.org/10.1016/j.oralo ncology.2009.03.003

30. Singer S, Wollbruck D, Wulke C, Dietz A, Klemm E, Oeken J, Meister EF, Gudziol H, Bindewald J, Schwarz R (2009) Validation 
of the EORTC QLQ-C30 and EORTC QLQ-H\&N35 in patients with laryngeal cancer after surgery. Head Neck 31(1):64-76. https://doi.org/10.1002/hed.20938

31. Sherman AC, Simonton S, Adams DC, Vural E, Owens B, Hanna E (2000) Assessing quality of life in patients with head and neck cancer: cross-validation of the European Organization for Research and Treatment of Cancer (EORTC) Quality of Life Head and Neck module (QLQ-H\&N35). Arch Otolaryngol Head Neck Surg 126(4):459-467

32. McHorney CA, Robbins J, Lomax K, Rosenbek JC, Chignell K, Kramer AE, Bricker DE (2002) The SWAL-QOL and SWALCARE outcomes tool for oropharyngeal dysphagia in adults: III. Documentation of reliability and validity. Dysphagia 17(2):97114. https://doi.org/10.1007/s00455-001-0109-1

33. Schober P, Boer C, Schwarte LA (2018) Correlation coefficients: appropriate use and interpretation. Anesth Analg 126(5):17631768. https://doi.org/10.1213/Ane.0000000000002864

34. Armstrong RA (2014) When to use the Bonferroni correction. Ophthalmic Physiol Opt 34(5):502-508. https://doi.org/10.1111/ opo. 12131

35. van der Molen L, van Rossum MA, Ackerstaff AH, Smeele LE, Rasch CR, Hilgers FJ (2009) Pretreatment organ function in patients with advanced head and neck cancer: clinical outcome measures and patients' views. BMC Ear Nose Throat Disord 9:10. https://doi.org/10.1186/1472-6815-9-10

36. Eisbruch A, Kim HJ, Terrell JE, Marsh LH, Dawson LA, Ship JA (2001) Xerostomia and its predictors following parotid-sparing irradiation of head-and-neck cancer. Int J Radiat Oncol Biol Phys 50(3):695-704

37. Jensen K, Lambertsen K, Torkov P, Dahl M, Jensen AB, Grau C (2007) Patient assessed symptoms are poor predictors of objective findings. Results from a cross sectional study in patients treated with radiotherapy for pharyngeal cancer. Acta oncologica 46(8):1159-1168. https://doi.org/10.1080/02841860701491041

38. Vlagsma TT, Koerts J, Tucha O, Dijkstra HT, Duits AA, van Laar T, Spikman JM (2017) Objective versus subjective measures of executive functions: predictors of participation and quality of life in Parkinson disease? Arch Phys Med Rehabil 98(11):2181-2187. https://doi.org/10.1016/j.apmr.2017.03.016

39. Hayhurst KP, Massie JA, Dunn G, Lewis SW, Drake RJ (2014) Validity of subjective versus objective quality of life assessment in people with schizophrenia. BMC Psychiatry 14:365. https://doi. org/10.1186/s12888-014-0365-X

40. Lycke M, Lefebvre T, Pottel L, Pottel H, Ketelaars L, Stellamans K, Van Eygen K, Vergauwe P, Werbrouck P, Cool L, Boterberg T, Liefhooghe N, Schofield P, Debruyne PR (2019) Subjective, but not objective, cognitive complaints impact long-term quality of life in cancer patients. J Psychosoc Oncol 37(4):427-440. https:// doi.org/10.1080/07347332.2018.1504154

41. Wilson JA, Carding PN, Patterson JM (2011) Dysphagia after nonsurgical head and neck cancer treatment: patients' perspectives. Otolaryngol Head Neck Surg 145(5):767-771. https://doi. org/10.1177/0194599811414506

42. Felce D, Perry J (1995) Quality of life: its definition and measurement. Res Dev Disabil 16(1):51-74

43. Lalla RV, Treister N, Sollecito T, Schmidt B, Patton LL, Mohammadi K, Hodges JS, Brennan MT, OraRad Study G (2017) Oral complications at 6 months after radiation therapy for head and neck cancer. Oral Dis 23(8):1134-1143. https://doi.org/10.1111/ odi. 12710

44. Chen AY, Frankowski R, Bishop-Leone J, Hebert T, Leyk S, Lewin J, Goepfert H (2001) The development and validation of a dysphagia-specific quality-of-life questionnaire for patients with head and neck cancer: the M. D. Anderson dysphagia inventory. Arch Otolaryngol Head Neck Surg 127(7):870-876

Publisher's note Springer Nature remains neutral with regard to jurisdictional claims in published maps and institutional affiliations. 